
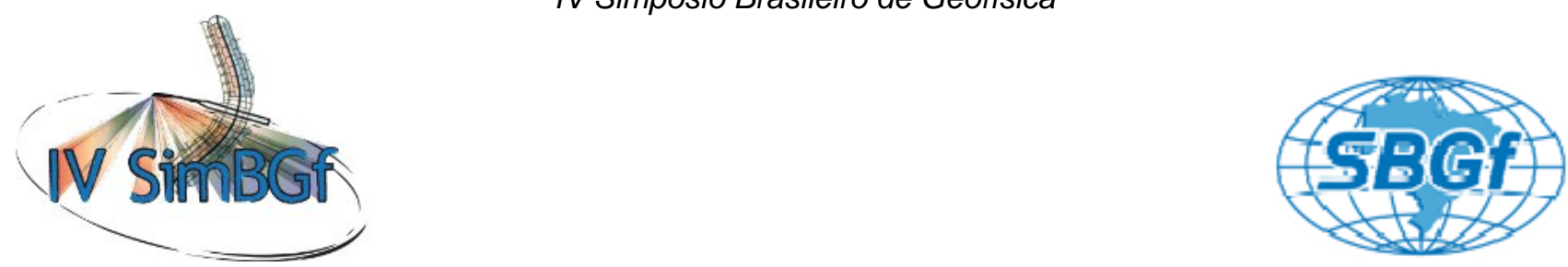

\title{
SÍSMICA RASA APLICADA AO ESTUDO DE AMBIENTES DEPOSICIONAIS E ARQUITETURA DE FACIES NO BAIXO CURSO DO RIO TOCANTINS (PA)
}

\author{
MARCO IANNIRUBERTO ${ }^{1}$, JOSÉ ELOI GUIMARÃES CAMPOS ${ }^{1}$ e VITTO CÉSAR MIRANDA DE ARAÚJO ${ }^{1}$ \\ ${ }^{1}$ Universidade de Brasília, Instituto de Geociências, Campus Universitário Darcy Ribeiro, 71900-000, \\ Brasília/DF, Brasil
}

Copyright 2010, SBGf - Sociedade Brasileira de Geofísica

Este texto foi preparado para a apresentação no IV Simpósio Brasileiro de Geofísica, Brasília, 14 a 17 de novembro de 2010. Seu conteúdo foi revisado pelo Comite Técnico do IV SimBGf, mas não necessariamente representa a opinião da SBGf ou de seus associados. É proibida a reprodução total ou parcial deste material para propósitos comerciais sem prévia autorização da SBGf.

\section{Resumo}

High-resolution seismic profiling was used to investigate sedimentary structures of lower course of Tocantins River, in the Amazon Basin, between the town of Tucuruí and the village Nazaré dos Patos. The methodology revealed to be extremely efficient to detect sedimentary facies of recent alluvional channels. The collected profiles show the impressive variety and complexity of architectural elements and internal structure of sandy macroforms. Analyses of the results allowed the identification of three environments, related to sedimentary processes active in the channel: by-pass, transition and deposition environments that correspond to current and channel dynamics and bedrock topography.

\section{Introdução}

Métodos de prospecção acústicos e eletromagnéticos têm sido amplamente utilizados nos estudos de fácies morfológicas e estrutura interna de barras e dunas de areia em ambiente fluvial e marinho, para descrever as seqüências deposicionais antigas e modernas, bem como provir dados para modelos sedimentológicos (Sambrook Smith et al., 2006; Hugenholtz et al., 2007).

Neste estudo, um perfilador acústico foi utilizado para investigar a estratigrafia do baixo curso do rio Tocantins, entre a cidade de Tucuruí e a vila de Nazaré dos Patos (Figura 1). O interesse se deve às possíveis mudanças do regime fluvial decorrente da implantação da barragem da UHE de Tucuruí e a perspectiva que este trecho se torne navegável assim que for completada a construção da respectiva eclusa.

$\mathrm{Na}$ maioria dos casos, a implantação de uma barragem comporta redução da descarga, decorrente das perdas de armazenamento e evaporação, e diminuição da capacidade de transporte de sedimentos (Brandt, 1995). Em termos de descarga de sedimentos, Williams \& Wolman (1994, apud Brandt, 1995) avaliaram a eficiência de retenção para grandes reservatórios ser maior de $99 \%$ para a carga de leito, resultando em um fluxo, a jusante da barragem, cuja capacidade de transporte é bem maior que a carga efetiva.
Do ponto de vista da caracterização hidrossedimentológica, o trecho do rio Tocantins a jusante da barragem da UHE de Tucuruí, conforme reportado por Lima (2003), é caracterizado por valores baixos de concentração e descarga de sedimentos em suspensão. O citado autor, com base em dados medidos na estação de Tucuruí no período de 1981 a 1998, determinou valores médios de $9 \mathrm{mg} / \mathrm{L}$ para a concentração e 8.388 t/dia para a descarga de sedimentos em suspensão.

Estes valores baixos de fluxo de sedimentos em suspensão a jusante da barragem de Tucuruí induz a pensar que o processo de sedimentação neste trecho do rio é essencialmente determinado pela carga do leito, sendo o efeito da carga dissolvida de importância menor nos rios brasileiros (Christofoletti, 1981).

Por outro lado, a diminuição da carga em suspensão torna as águas "famintas" de sedimentos, com conseqüente erosão das margens e do leito a jusante da barragem, até que esta produção local de sedimentos não equilibre o potencial de transporte do fluxo. (Williams \& Wolman, 1985)

Com base nestas considerações, pode-se inferir que os sedimentos que compõem as feições individualizadas no levantamento sísmico são do período anterior ao preenchimento da barragem ou oriundos de processos de erosão e re-mobilização de formas de leito a jusante da barragem.

\section{Metodologia/ Problema Investigado}

O trabalho visa descrever as fácies acústicas e arquiteturais do leito do rio associadas com os mecanismos de transporte e deposição de sedimentos, considerando também a importância dos mesmos sobre a possível implantação de uma hidrovia.

O método utilizado para o levantamento é baseado no uso de um sistema de sísmica rasa (perfilador de subfundo) de alta resolução, com interface com um sistema de posicionamento WADGPS e o software de navegação e aquisição de dados (Hypack/Hysweep). O perfilador de subfundo utilizado foi o Edgetech 3100P com o transdutor SB-216S que emite um pulso "chirp" modulado em frequência na banda $2-16 \mathrm{kHz}$, e permitiu alcançar penetração de até $10 \mathrm{~m}$ em camadas de areia, com uma resolução de cerca de $10 \mathrm{~cm}$.

O posicionamento do navio e dos sensores foi realizado mediante o sistema de satélite WASGPS Trimble 
DMS232, com correções diferenciais via sistema Amsat, que, mediante o software Hypack/Hysweep permite amarração do sistema de coordenadas para todos os sensores instalados a bordo, com precisão horizontal estimada de cerca de $10 \mathrm{~cm}$.

O levantamento foi conduzido realizando linhas de navegação paralelas ao canal navegável do rio, com algumas seções transversais realizadas para controle dos dados batimétricos e para avaliar a continuidade lateral das estruturas sedimentares. Ao todo, foram adquiridos cerca de $120 \mathrm{~km}$ de linhas sísmicas.

A área estudada se localiza no centro-norte do Estado do Pará, na borda ocidental da Bacia do Parnaíba, caracterizada por um contexto geológico que inclui o embasamento da Bacia do Parnaíba, além de sucessões cenozóicas relacionadas ao Grupo Barreiras e aos depósitos aluvionais do rio Tocantins. da Bacia do Parnaíba, além de sucessões cenozóicas relacionadas ao Grupo Barreiras e aos aluviões do rio Tocantins. Conforme Barbosa (1966), a área corresponde a uma zona de transição entre o embasamento cristalino - Complexo Xingu, localizado na margem esquerda do rio, e uma seqüência vulcano-sedimentar, com metamorfismo de baixo grau (Formação Tucuruí), composto de depósitos terciários, além de deposições quaternárias, que constituem o aluvião.

Os registros geofísicos mostraram nitidamente a estrutura interna das barras fluviais, onde a variação de impedância acústica que gera as reflexões se deve a variação da sedimentação ligada a eventos cíclicos. A caracterização do material foi realizada em observação de barras emersas e parcialmente erodidas na margem de uma ilha (Figura 2) que permitiu identificar camadas de sedimento com baixo grau de selecionamento, de espessura de alguns decímetros, que podem ser associadas a eventos extremos de descarga, inundação

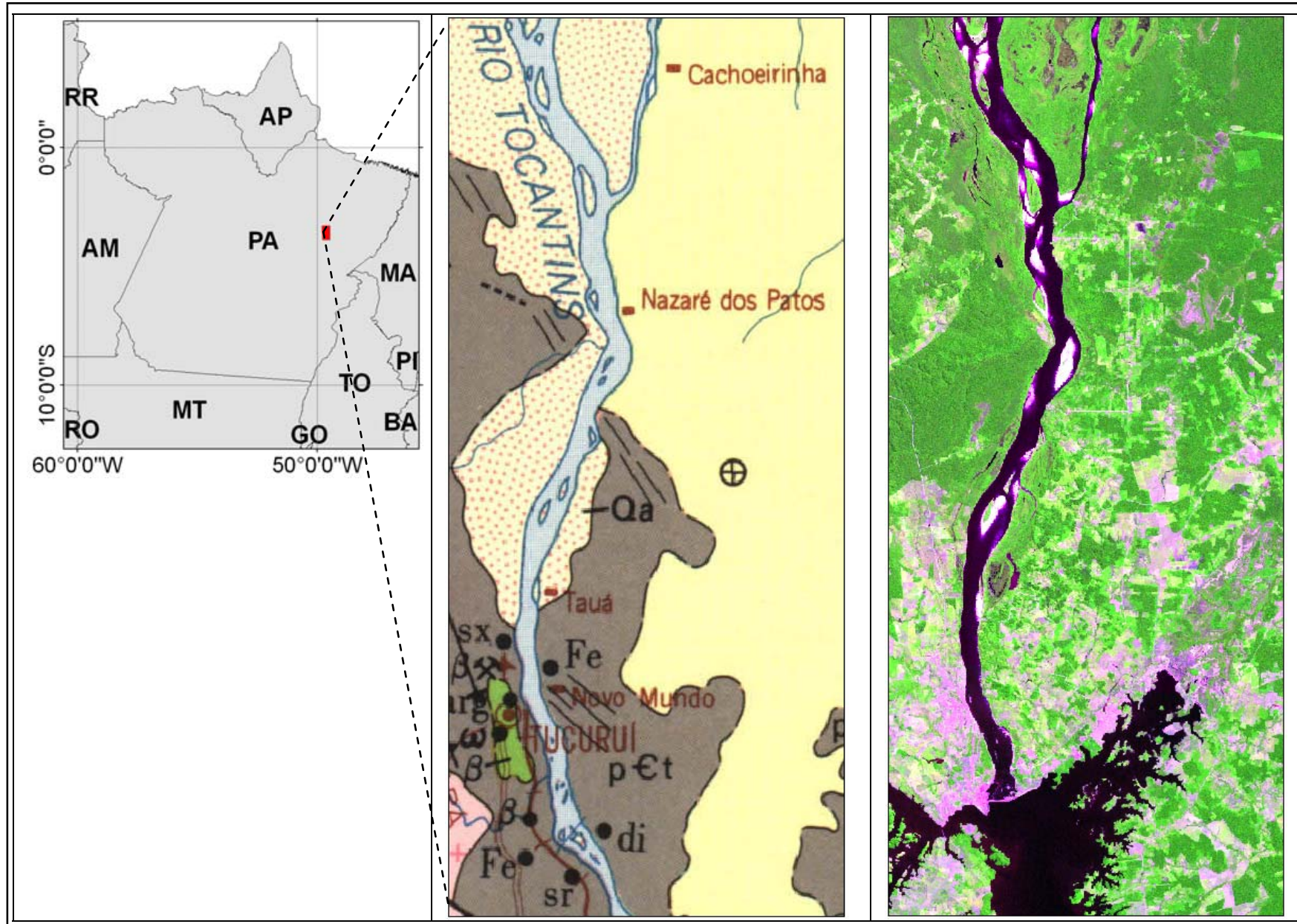

Figura 1: Mapa de localização da área de estudo. Imagem central: Mapa geológico (Projeto Radam Brasil,1974). Imagem a direita: Mosaico colorido LANDSAT TM 224-62 e 224-63 (2001).

\section{Resultados}

O trecho da pesquisa se encontra no baixo curso do rio Tocantins e compreende linhas de navegação entre a cidade de Tucuruí e a cidade de Nazaré dos Patos. Possui um contexto geológico que inclui o embasamento das margens, erosão e reativação da deposição. Considerando o efeito de contenção das cheias e regularização do fluxo devido á presença do reservatório da UHE, é presumível que tais eventos sejam relativos ao período anterior ao preenchimento do reservatório. 
A integração dos dados levantados nas seções geofísicas e nos respectivos recortes com as informações das esparsas exposições em cortes de barrancos e praias mostram que o sistema fluvial em estudo é amplamente dominado pela deposição de areia. Os materiais pelíticos (silte e argila) certamente estão presentes no sistema de deposição como um todo, mas sua sedimentação é exclusiva das planícies de inundação, as quais não foram contempladas no trecho fluvial estudado (apenas foi levantado o canal ativo atual).

$\mathrm{Na}$ porção de canal ativo estudado neste levantamento foi possível determinar três condições de transportedeposição, incluindo áreas de by pass, com erosão e transporte acentuados, áreas de deposição, com acumulação de areia em diferentes condições de fluxo e áreas de transição, associadas à interdigitação das anteriores.

É importante observar que as distintas formas de leito são fortemente vinculadas a paleo-topografia do embasamento, de forma que os leitos em formas de dunas ou barras são gerados sobre fundos com topografia irregular (observação válida para os casos de imagens geofísicas em que é possível definir o embasamento).

A seguir serão apresentados exemplos de imagens geofísicas em diferentes contextos com as respectivas descrições de fácies e processos sedimentares envolvidos.

Ambientes de by pass

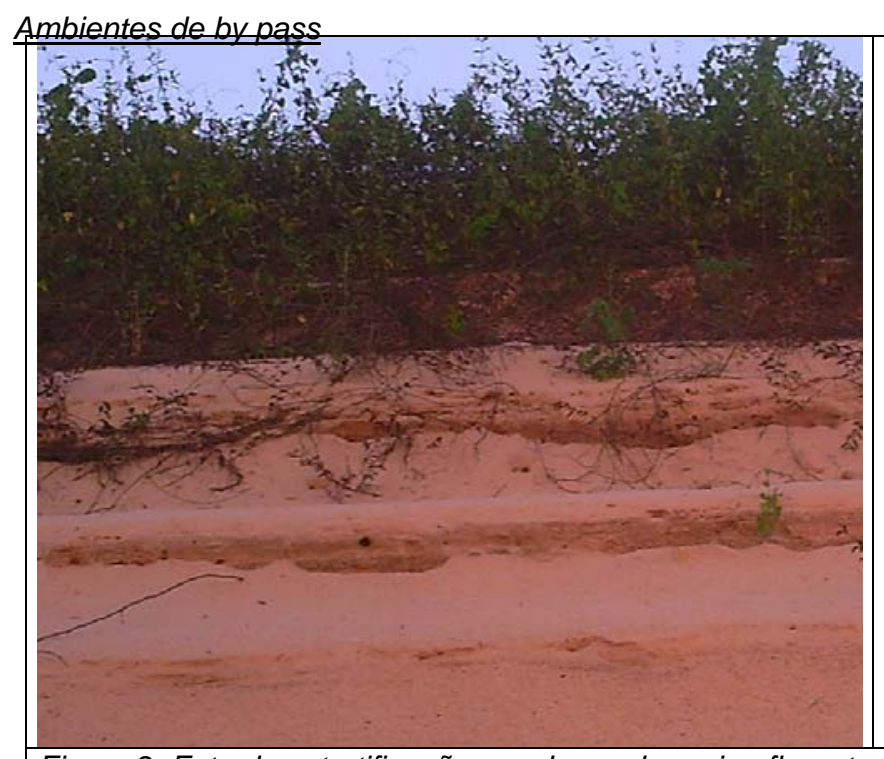

\section{Ambientes de deposição}

outros casos pode resultar em fortes assimetrias, com maiores profundidades deslocadas em direção a uma das margens.

A figura 3 mostra exemplo deste tipo de ambiente, onde o fundo do rio tem relevo ondulado e não há refletores indicando acumulação de sedimentos. Nesta figura há uma nítida tendência que destaca planos inclinados para norte, os quais são interpretados como plano de foliação de xistos ou como um sistema de fraturas de alta densidade.

Localmente podem ocorrer canais com mais de 10 metros de amplitude o que é interpretado como produto da erosão pela turbulência do fluxo e por correntes em vórtices.

Quando o canal fluvial alcança profundidade maior que 20 metros o atrito da corrente com o fundo causa a dissipação da energia e a capacidade de transporte é drasticamente reduzida e iniciam os processos de deposição. A figura 4 apresenta um exemplo deste tipo de ambiente, onde no centro do vale há preenchimento por materiais arenosos maciços ou por misturas de areias e lamas. Ao norte a sul do canal o leito do rio é diretamente desenvolvido em rocha. Este tipo de estrutura geneticamente é interpretado como vinculado a zona de fraqueza do embasamento (zona de falha ou contato de rochas com contraste de resistência).

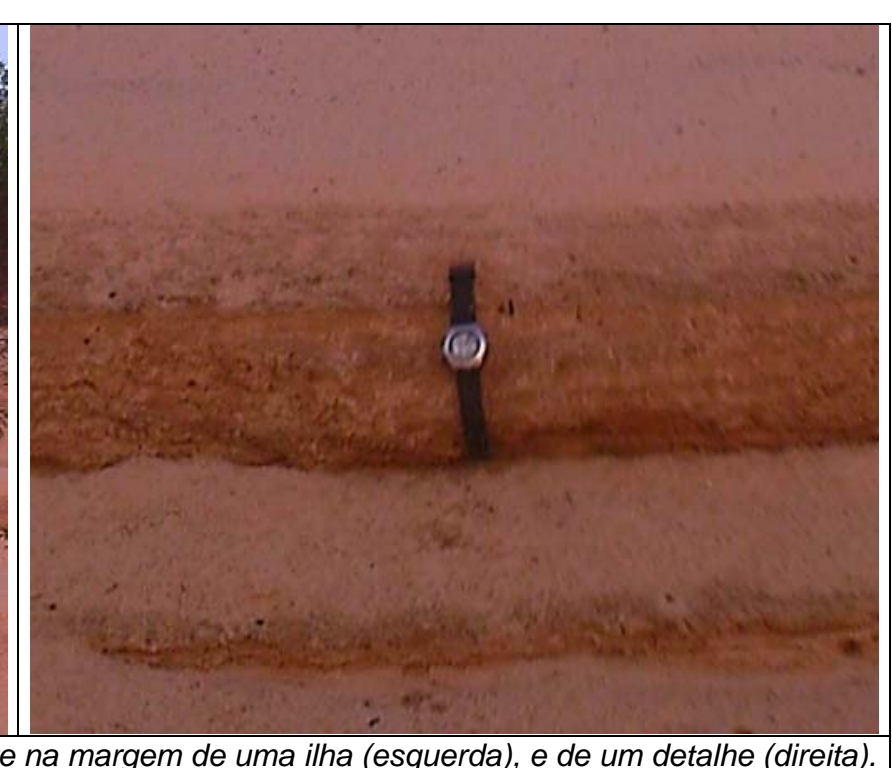

Nos ambientes de by pass ou de erosão dominam os processos de transporte por arraste, saltação e suspensão. De forma geral estes ambientes expõem diretamente o embasamento local e apresentam profundidades de até 20 metros.

Estes ambientes são mais comumente observados ao longo dos canais principais e mais raramente ocorrem em posições marginais do rio. Os canais principais podem ocorrer na porção central do eixo fluvial atual, mas em
$\mathrm{Na}$ figura 5 é apresentado um conjunto de barras longitudinais, com refletores internos que marcam estratos plano-paralelos, que podem ocorrer internamente laminados ou compondo sets de estratos cruzados de menor ordem.

$\mathrm{Na}$ porção frontal das barras o conjunto apresenta inclinação em direção ao sentido do fluxo, o que mostra a tendência de migração destas macro-formas. Estas feições mostram sítios deposicionais e resultam em 
elementos arquiteturais do tipo acresção longitudinal. O processo sedimentar que domina na formação deste conjunto é do tipo transporte por tração e saltação e deposição pela gradual diminuição da energia.

É interessante observar que a barra ao centro da figura (exagero vertical 6:1) tem uma altura de cerca de 6 metros relativamente ao talvegue, com uma pendência de $50 \%\left(27^{\circ}\right)$.

O exemplo apresentado na Figura 6 mostra um sítio de deposição pouco espesso diretamente sobre o embasamento caracterizado por irregularidades de fundo. Neste caso as estruturas internas às barras são dominantemente estratificações plano-paralelas. A macro-forma ondulada é interpretada como o topo e corpo de barras transversais ao sentido de migração principal do fluxo. O conjunto representa uma seqüência de elementos arquiteturais de acresção lateral com migração de fácies arenosas a partir de fluxo por tração. Algumas seções, como exemplificado pela figura 7, mostram clinoformas de grande porte que evidenciam linhas de tempo com a migração longitudinal da forma de leito em macro ondulações. Os refletores mais evidentes são interpretados como os planos de reativação da sedimentação que neste caso deve ter forte caráter sazonal.

$\mathrm{Na}$ porção SW da seção o topo da barra é fortemente ondulado como provável resposta da turbulência do fluxo. No extremo NE da seção o conjunto de estratos em acamamento horizontal é considerado como produto de fluxo dominantemente laminar que compõe o elemento arquitetural tipo areias laminadas.

\section{Ambientes de transição}

Os ambientes de transição se desenvolvem na passagem entre sítios deposicionais e área de by pass e podem ocorrer ao longo do eixo longitudinal do rio e transversalmente ao canal atual. Os condicionantes destes sítios são atribuídos a pelo menos dois controles: variações na resistência do material que compõem o embasamento local e mudanças laterais / longitudinais na energia e padrão da corrente.

A figura 8 traz um exemplo de condição de transição onde a deposição fluvial (porção centro-nordeste da imagem) se dá em padrão complexo imediatamente depois de longo trecho do rio sob fundo rochoso.

$\mathrm{Na}$ figura 9 é representado um exemplo de ambiente transicional com relevo de embasamento irregular que passa na porção sul de condições de depósitos mais rasos (até 5 metros de espessura) para um pacote $\mathrm{cm}$ ais de 10 metros de espessura ao norte. O conjunto forma uma arquitetura de fácies classificada como forma de leito arenosa. Localmente os ambientes transicionais são observados após longos trechos de leito rochoso e apresentam arranjo complexo de fácies arenosas, com registros de refletores inclinados formando sigmóides que indicam o contraste de energia e profundidade do ambiente. Neste caso o sítio deposicional local pode ser comparado à sedimentação em condições deltáicas. O relevo de fundo igualmente apresente controle na arquitetura do depósito formado.

\section{Discussão e Conclusões}

O baixo curso do rio Tocantins é classificado como do tipo anastomosado, sendo a deposição arenosa predominante no leito e a deposição pelítica mais expressiva apenas nas planícies de inundação.

Em particular, no trecho em analise, observa-se a progressiva evolução do padrão de planform, de retilíneo, logo a jusante da barragem, a anastomosado, para jusante da vila de Nazaré dos Patos. Analise comparativa das imagens de satélite atuais com mapa do projeto RADAM Brasil, 1974, não permite avaliar mudanças significativas na planform do rio. Por outro lado, as seções geofísicas possibilitam definir sítios erosivos, deposicionais e transicionais que se intercalam longitudinal e transversalmente com relação ao canal do rio atual.

A presença destes ambientes, além de ser controlada pela profundidade do canal e tipo de fluxo, parece relacionada a distância da barragem, pois os primeiros dezoito quilômetros a jusante da barragem mostram uma prevalência de ambientes de by-pass, que poderiam ser relacionados aos efeitos erosivos da descarga desprovida de sedimentos. Mais a jusante, o equilíbrio na carga sedimentar poderia ser re-estabelecido pela erosão do fundo e das margens do rio, e os registros acústicos mostram a presencia contínua de barras transversais de areia.

A pesquisa verificou a possibilidade de aplicação da metodologia para estudar a arquitetura interna submersa das barras, que, em combinação com técnicas de amostragem e datação, poderia fornecer um modelo da evolução temporal do processo de sedimentação antes de depois da formação do reservatório.

\section{Agradecimentos}

Os autores agradecem o Prof. Augusto César Bittencourt Pires pela revisão do texto e pelas preciosas sugestões. O estudo foi parcialmente financiado com recursos do Projeto "Levantamentos Hidrográficos e Cartografia Eletrônica para Segurança da Navegação em Hidrovias", financiado pelo Fundo MCT/FINEP - CT -AQUAVIÁRIO 01/2006.

\section{Referências}

Barbosa O. Ramos, J.R.A., Gomes, F.A.; Hembold, R. 1966. Geologia estratigráfica, estrutural e econômica da área do Projeto Araguaia. DNPM, Divisão de Geologia e Mineralogia, Rio de Janeiro, Monografia 19, 94 pp.

Brandt, S.A., 2000. Classification of geomorphological effects downstream of dams. Institute of Geography, University of Copenhagen, Øster Voldgade 10, DK-1350 Copenhagen, Denmark

Brasil Ministério das Minas e Energia, 1974a. Projeto Radambrasil Folha SB.22 Araguaia e Parte da Folha 
SC.22 Tocantins; geologia, geomorfologia, solos, vegetação e uso potencial da terra. Rio de Janeiro, Brasil.

Christofoletti, A., 1981. Geomorfologia Fluvial. São Paulo, Edgard Blucher Ltda. 313 p.

Hugenholtz, C. H., Moorman, B. J., Wolfe, S. A., 2007. Ground penetrating radar (GPR) imaging of the internal structure of an active parabolic sand dune. In Stratigraphic Analyses Using Gpr. (Eds) Gregory S. Baker, Harry M. Jol, Geological Society of America, Special paper 432, pp. 35-45.

Lima, J.E.F.W., Santos, PM. C. dos, Carvalho, N. de O., Silva, E.M. da. 2003. Diagnóstico do fluxo de sedimentos em suspensão na Bacia Araguaia-Tocantins. Planaltina, DF, Embrapa Cerrados, Brasília, DF, ANEEL: ANA. 116 p.

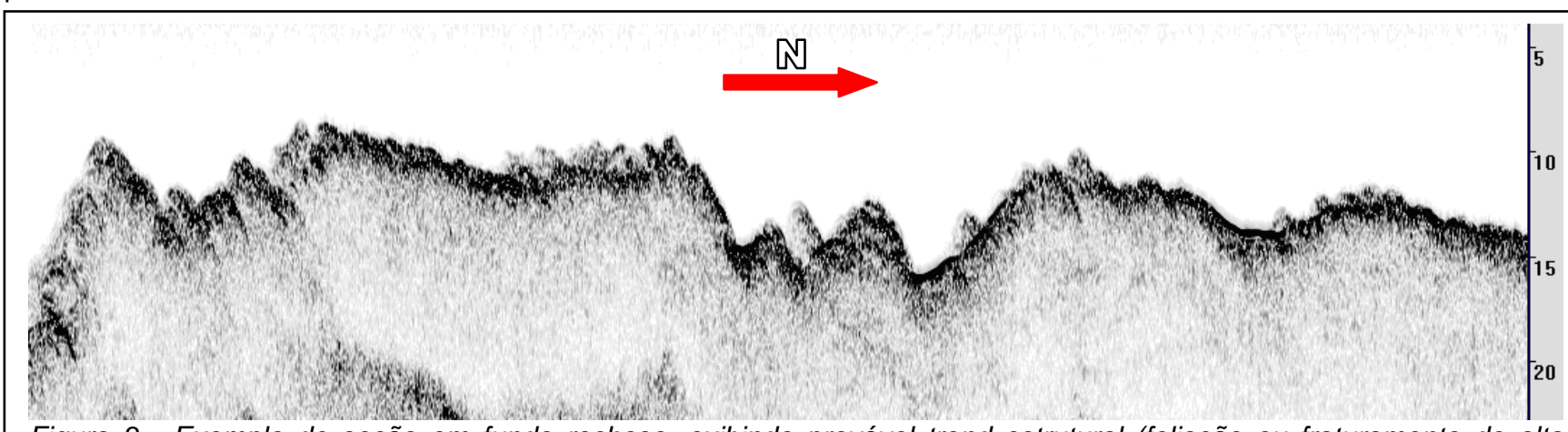

Figura 3 - Exemplo de seção em fundo rochoso, exibindo provável trend estrutural (foliação ou fraturamento de alta densidade). Trecho com 527m.

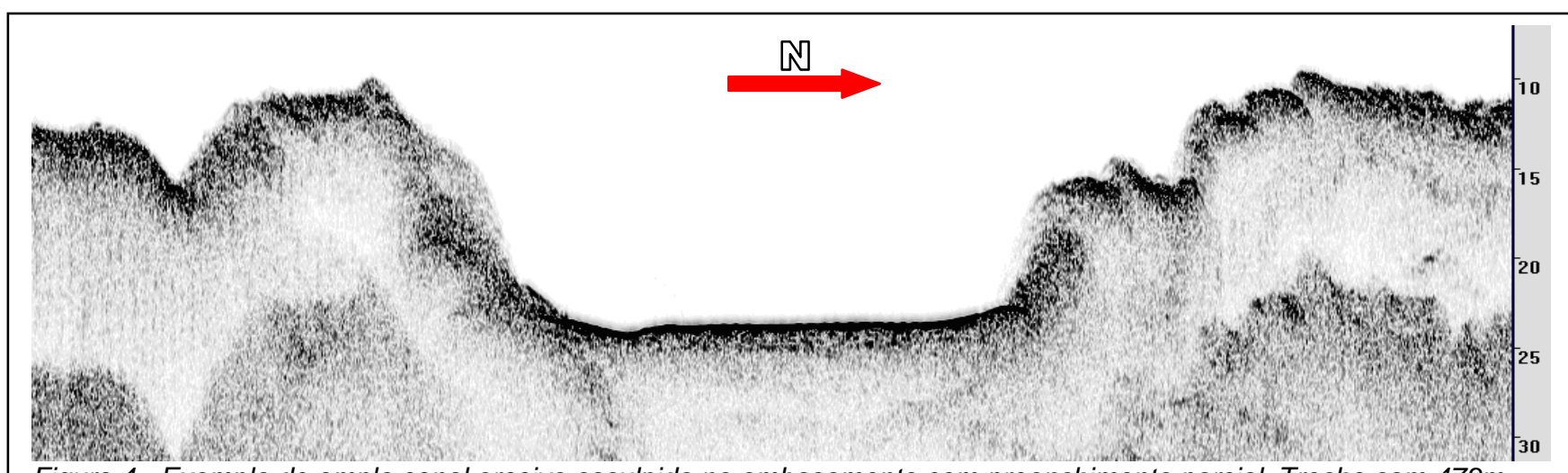

Figura 4 - Exemplo de amplo canal erosivo esculpido no embasamento com preenchimento parcial. Trecho com $473 m$.

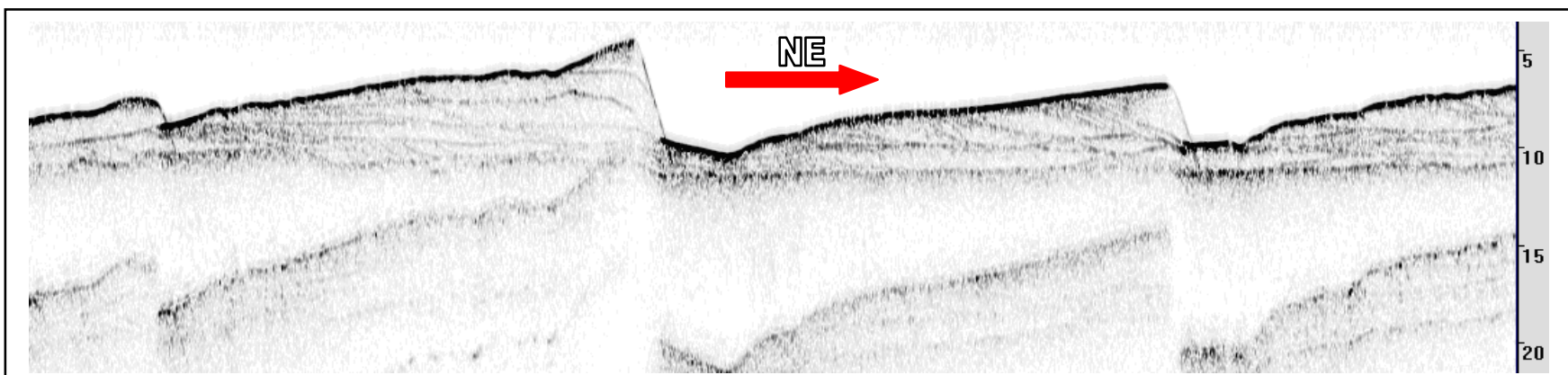

Figura 5 - Exemplo de estrutura de barras, compondo um conjunto de elemento arquitetural de acresção longitudinal. Trecho com $514 m$
Sambrook Smith, G.H., Ashworth, P.J., Best, J.L., Woodward, J., Simpson, C.J. 2006. The sedimentology and alluvial architecture of the sandy braided South 2, pp. 413-434.

Williams, G.P. \& Wolman, M.G. 1985. Downstream Survey Professional Paper 1286. 83 p. il. effects of dams on alluvial rivers. Washington, Geological 

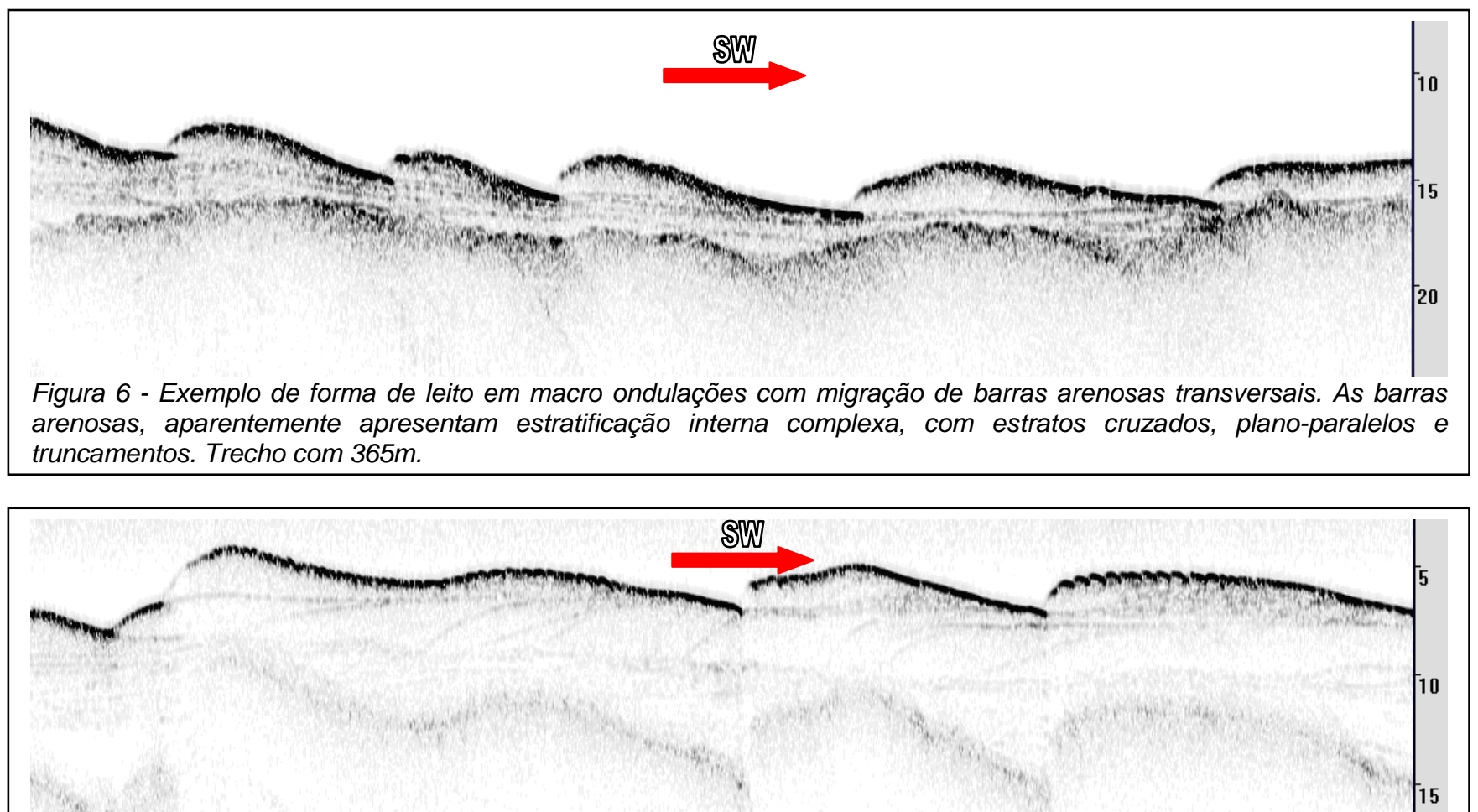

Figura 7 - Depósitos de migração lateral do canal marcada pelas clinoformas de grande porte que representam migração lateral do canal com deposição de areias e grauvacas. O trecho apresenta 400m.

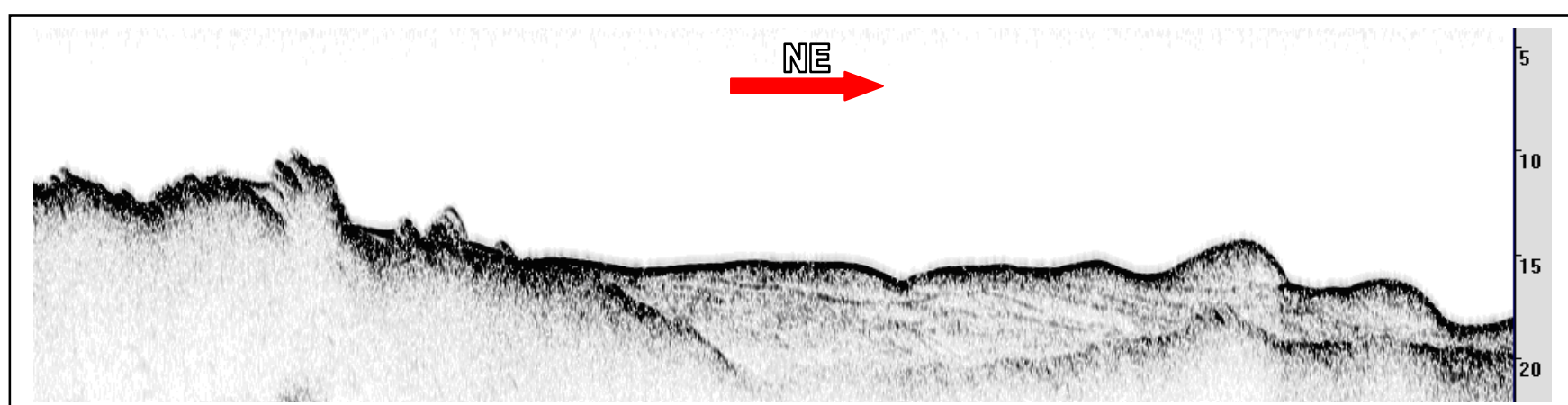

Figura 8 - Transição entre ambiente de fundo rochoso e sítio deposicional. A deposição das areias em padrão inclinado em baixo ângulo para jusante indica atuação de correntes tangenciais. Trecho com $472 \mathrm{~m}$.

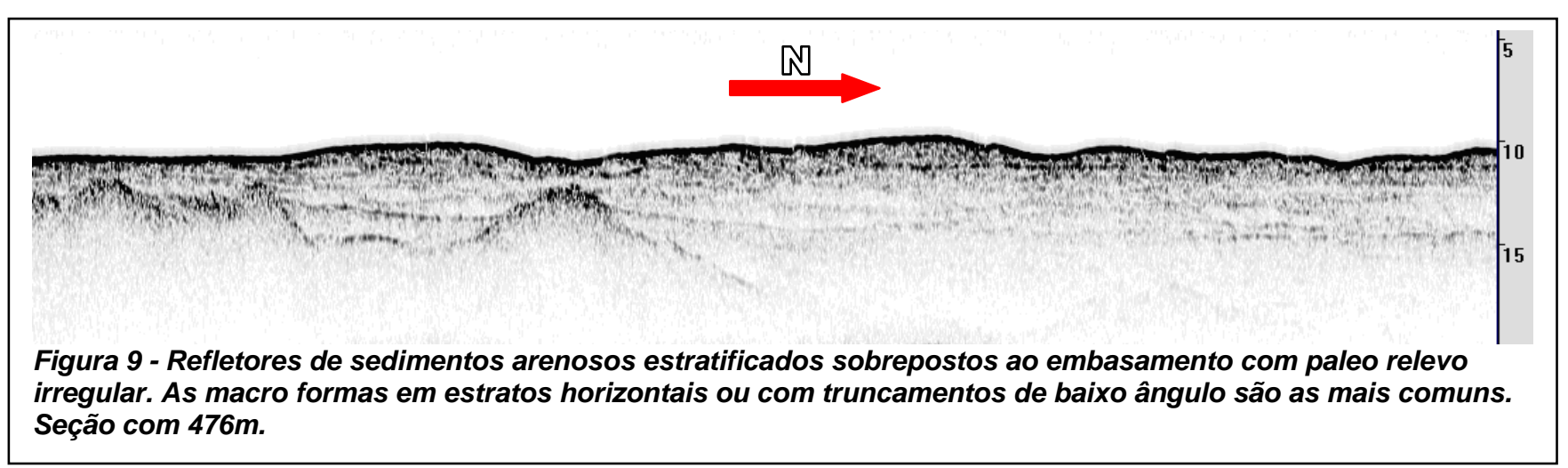

